\title{
Esperança e qualidade de vida de envelhescentes que se relacionam com pessoas do mesmo sexo
}

João Paulo Ferreira da Silva. Universidade Federal de São Carlos.

Keika Inouye. Universidade Federal de São Carlos.

Fabiana de Souza Orlandi. Universidade Federal de São Carlos.

Sofia Cristina lost Pavarini. Universidade Federal de São Carlos.

\section{Resumo}

Esta pesquisa teve como objetivo comparar os níveis de esperança e a qualidade de vida de uma amostra de indivíduos envelhescentes (na faixa dos 40 aos 65 anos) que se relacionam com pessoas do mesmo sexo de maneira secreta e aberta à sociedade. Os instrumentos utilizados para coleta de dados foram: Escala de Esperança de Herth (EEH) e WHOQOL-bref. A amostra foi dividida em grupos: (a) GAon ( $n=52$ ): envelhescentes que se relacionam com pessoas do mesmo sexo de forma aberta à sociedade; (b) GFoff ( $n=51$ ): envelhescentes que mantém a homossexualidade de maneira secreta. Os dados mostraram que o GFoff apresenta escores qualidade de vida (domínios psicológico, relações sociais e meio ambiente) e esperança mais elevados quando comparados com o GAon.

Palavras-chave: gerontologia; envelhecimento; homossexualidade; qualidade de vida; esperança.

\begin{abstract}
Hope and quality of life of mature people who have a relationship with same sex people. This research aimed to compare the levels of hope and quality of life of a sample of mature individuals (in the range of 40 to 65 years old) who have relationship to same sex people in a secret and open manner to society. The instruments used for data collection were: Hope Scale of Herth (EEH) and WHOQOL-bref. The sample was divided into groups: (a) GAon $(n=52)$ : aging people who have relationship with same sex people in an open society; (b) GFoff $(n=51)$ : aging people who maintains their homosexual status in a secret manner. The data showed that the GFoff presents higher scores of quality of life (psychological, social relationships and environment) and higher hope compared to the GAon group.
\end{abstract}

Keywords: gerontology; aging; homosexuality; quality of life; hope.

\section{Resumen}

La esperanza y la calidad de vida de envejecientes que se relacionan con personas del mismo sexo. Esta investigación tuvo como objetivo comparar los niveles de la esperanza y la calidad de vida de una muestra de individuos maduros (en el rango de 40 a 65 años) que tienen relación con personas del mismo sexo de una manera secreta y abierta a la sociedad. Los instrumentos utilizados para la recolección de datos fueron: Esperanza Escala de Herth (EEH) y WHOQOL-BREF. La muestra se dividió en grupos: (a) GAon ( $n=52$ ): personas de edad avanzada que tienen relación con personas del mismo sexo en una sociedad abierta; (b) GFoff $(n=51)$ : personas de edad avanzada, que mantiene su condición homosexual de manera secreta. Los datos mostraron que la GFoff presenta puntajes más altos de calidad de vida (psicológico, relaciones sociales y medio ambiente) y una mayor esperanza en comparación con el grupo GAon.

Palabras clave: gerontología; envejecimiento; homosexualidad; calidad de vida; esperanza. 
Cada indivíduo, com padrões específicos relacionados à idade, classe social, raça, etnia, geração, gênero, sexualidade etc., é dotado de potenciais que podem levar a uma vida plena com boa qualidade de vida e autorrealização, se apoio social e recursos adequados forem providos (Inouye, 2008; Mendes, Nunes, \& Ferreira, 2002). Na mesma medida, a falta de apoio, ausência de recursos e suporte social, somado aos estereótipos negativos podem acarretar em adversidades na vida das pessoas. $\mathrm{O}$ isolamento social e desdobramentos psicológicos negativos podem fazer parte da identidade de muitos envelhescentes que se relacionam com pessoas do mesmo sexo passando da meia-idade à velhice até sua finitude (Simões, 2004).

Numa perspectiva atenta à questão geracional, pessoas envelhescentes que nasceram entre os anos 1960 e 1970 vivenciaram ao menos dois momentos históricos comuns: $\left(1^{\circ}\right)$ o pânico sexual da epidemia de HIV-aids nos anos 1980 e $\left(2^{\circ}\right)$ o advento da internet comercial a partir de 1997 no Brasil. Assim, consideramos importante retraçar esses dois momentos a partir do aspecto geracional, uma vez que eles produziram efeitos sobre a compreensão social acerca da homossexualidade e sociabilidade homoerótica, como aponta a literatura (Miskolci \& Pelúcio, 2009; Perlongher, 2008; Pollak, 1990).

O sociólogo austríaco Pollak (1990) analisa que a produção do discurso médico sobre a AIDS a partir de fins de 1985 pela imprensa jornalística e também pela epidemiologia envolveu uma noção moralizante por meio da qual criou grupos de risco, sem claras evidências empíricas, baseando-se frequentemente em aspectos tocantes à sexualidade, classe, etnia, raça e origem social. Os primeiros grupos de risco foram os homossexuais e os imigrantes haitianos e porto-riquenhos, incluindo a posteriori as prostitutas e usuários de drogas endovenosas (Pollak, 1990).

A AIDS, nos anos 1980, foi primeiramente denominada como GRID (Gay Related Imune Deficiency ou Deficiência Imunológica Relacionada à Homossexualidade); tal expressão recolhia uma espécie de ligação natural entre homossexualidade e doença, o que rememorava o entendimento psiquiátrico sobre as relações entre o mesmo sexo, sobretudo pelo homossexualismo - terminologia mais vinculada ao campo da patologia e do desvio a qual integrou até 1973 a lista de distúrbios mentais da Associação Americana de Psicologia (APA). Segundo Simões e Facchini (2009):
Com a AIDS, reacendeu-se a ligação entre homossexualidade e doença. Expressões como "peste gay" espocaram e persistiram, mesmo depois de constatado que o vírus poderia ser transmitido a qualquer pessoa, através do sangue, esperma e outros fluidos corporais. Junto com o triste legado de intolerância, violência e morte, a epidemia escancarou também a presença socialmente disseminada de práticas homossexuais masculinas para além da população homossexual visível (p. 52).

Os espaços de circulação e sociabilidade entre o mesmo sexo, deste modo, passaram a incorporar questões morais de monta. Indivíduos que buscavam parceiros do mesmo sexo para relações amorosas e/ou sexuais no espaço público encontravam-se marcados de forma dupla, ora pelo próprio estigma em torno das homossexualidades ora pela patologização das relações - as quais, não raramente, eram tratadas como principal forma de contágio e disseminação da AIDS. Segundo Miskolci (2014), o processo de seleção de parceiros para sexo entre homossexuais nos anos 1980 passou por uma higienização rigorosa, no auge da epidemia de AIDS, em que "o pânico de se contaminar levou homens gays a buscar parceiros "fora do meio", pois - supunha-se - que se não frequentassem os ambientes gays, teriam menores chances de contaminação com o vírus HIV" (Miskolci, 2014, p. 283).

A resposta global à doença, de acordo com Susan Sontag (1989), foi fortemente acompanhada por um discurso moral que apresentava a AIDS como uma doença mortal associada à deterioração física, normalmente em corpos jovens, e também em sexualidades não-normativas (não-heterossexuais). Desse modo, a noção de "meio" tornou-se carregada e preocupante, sobretudo pela massiva repercussão dos comportamentos tidos pela medicina como de risco, os quais sinalizavam para as relações homossexuais. Sujeitos adeptos a relações homoeróticas, portanto, passaram a buscar pessoas fora das categorias de risco e, consequentemente, "fora do meio" homossexual.

$\mathrm{Na}$ internet, a partir dos anos 1990, a noção "fora do meio" se populariza entre homossexuais, abarcando um perfil que demanda "alguém discreto" e que busca socialização via bate-papo e ainda, mais recentemente, em aplicativos que funcionam a partir de smartphones. De qualquer forma, é preciso entrever que homens acima dos 45 anos, que são escolarizados e possuem acesso à internet, buscam online uma socialização historicamente negada e, inclusive, estigmatizada no espaço público e nas interações face a face. 
Não obstante, antes da internet comercial as práticas homoeróticas e as buscas tendem a prevalecer no espaço público, sobretudo em lugares socialmente marginalizados como, por exemplo, nos decadentes cinemas nas regiões centrais das grandes cidades, em ruas desertas, parques, praças, estacionamentos e banheiros públicos (Guimarães, 2004; Perlongher, 2008).

A internet, portanto, se caracteriza como um espaço novo em termos históricos e uma conquista no que toca ao estabelecimento de redes mais amplas e interconectadas, ligando sujeitos que vivem em cidades pequenas e médias, nos centros e nas periferias das regiões metropolitanas. A nova arquitetura comunicacional (Illouz, 2012), impulsionada pelo desenvolvimento dos dispositivos móveis e aplicativos na década de 2010, pelo crescimento econômico dos anos 2000 consagrado pelo acesso ao crédito às classes populares, a bens de consumo duráveis e a emergência das classes C e $D$, criou uma situação social distinta e inédita àquela vivenciada nos anos 1980 e 1990 (Scalon \& Salata, 2012; Souza, 2012).

Se em fins dos anos 1980 sujeitos que buscavam relações homoeróticas no espaço público foram perseguidos pelo pânico moral da AIDS e suas práticas foram socialmente repreendidas, contemporaneamente com o advento da internet comercial e das plataformas online de busca de parceiros as relações parecem ter ganhado novas possibilidades, inclusive no que concerne a viver a experiência homoerótica em segredo.

Outro ponto a ser considerado são as representações sociais de homens homossexuais envelhescentes. De acordo com a literatura, as representações podem abarcar a feminilidade e a fragilidade de modo a conceber sujeitos sem grandes expectativas, incorrendo até mesmo em figuras hiperssexualizadas e, por vezes, criminosas como o "velho tarado" ou o sujeito adepto a práticas pedófilas (Mota, 2009). Além do preconceito e dos estereótipos quotidianamente vivenciados, sujeitos envelhescentes que se relacionam com o mesmo sexo podem ter ao menos uma desvantagem, uma vez que estes geralmente não dispõem de filhos e dos vínculos familiares dos quais poderiam esperar apoio na velhice (Simões, 2004).

Acredita-se que as percepções de esperança e qualidade de vida podem ser influenciadas pelas dinâmicas sociais e as escolhas que cada sujeito faz de viver sua sexualidade. Assumir as relações homossexuais no espaço público, o que engloba deste modo o ambiente da família, do trabalho e do lazer, consiste em se colocar numa situação de visibilidade aos olhares das outras pessoas, aos possíveis julgamentos de valores, conflitos e a nomeações por diversas vezes depreciativas. Por outro lado, o assumir-se pode trazer também sentimentos de liberdade e realização. Na mesma medida, vivenciar relacionamentos homossexuais de maneira secreta também implica em sentimentos contraditórios e dificuldades. Sendo assim, este estudo busca investigar e comparar as percepções de esperança e qualidade de vida de pessoas envelhescentes que se relacionam com pessoas do mesmo sexo de modo público (a) e secreto/ privado (b), investigando por meio de uma metodologia atenta aos indicadores de qualidade de vida e esperança, quais são os impactos dessas duas condições sociais nas percepções subjetivas acerca dos indicadores gerados.

A esperança pode ser entendida como um sentimento que move o ser humano a crer em resultados positivos, relacionados a eventos e circunstâncias da vida. Ter esperança significa olhar para as oportunidades mesmo que em situações difíceis a fim de modificar uma situação ruim para uma melhor (Sartore \& Grossi, 2008).

A qualidade de vida reúne múltiplas dimensões, as quais envolvem percepções individuais e coletivas sobre si e também sobre o meio ambiente. Essas percepções, de acordo com a literatura, inter-relacionam bem-estar, desejabilidade, prazer e satisfação (Neri, 2008). Atualmente, a definição mais conhecida é a do grupo da Organização Mundial da Saúde (OMS) que define qualidade de vida como "a percepção do indivíduo de sua posição na vida, no contexto da cultura e sistemas de valores nos quais vive e em relação aos seus objetivos, expectativas, padrões e preocupações" (World Health Organization Quality of Life Working Group [WHOQOL], 1995, p. 1405). A definição apresentada esboça a qualidade de vida como um conceito bastante amplo, o qual incorpora os domínios de saúde física, estado psicológico, nível de independência, relações sociais, crenças pessoais e relação com aspectos significativos do meio ambiente (WHOQOL, 1998).

Fleck et al. (2000) e Fleck (2008), em revisão de literatura, aponta que uma "boa qualidade de vida" está presente quando as esperanças e as expectativas de um indivíduo modificadas pela idade, experiência, padrões sociais e culturais são satisfeitas.

A maneira pela qual as pessoas se relacionam afetivamente e buscam parceiros para sexo, amor ou amizade é algo subjetivo e que demanda uma trajetória 
pessoal e de reconhecimento de si em várias esferas sociais; assim sendo, não é mero acaso que sujeitos homossexuais tenham constantemente que negociar seus desejos afetivos e suas preferências pessoais no ambiente familiar, no espaço de trabalho e do lazer, os quais são fortemente marcados pelo que a autora feminista Adrienne Rich define como "heterossexualidade compulsória" (Rich, 1993). Para a autora as normas sociais que definem o nosso gênero e até mesmo a nossa sexualidade são estimuladas e produzidas numa matriz social que se organiza a partir da concepção heterossexual de sociedade.

Enquanto algumas pessoas assumem seus desejos e suas relações de forma pública, existem aquelas que vivenciam relacionamentos de forma secreta a fim de não confrontar a cultura heteronormativa demandada no espaço público nas relações habituais. No entanto, não se sabe qual é o impacto biopsicossocial nestas duas situações sociais tão distintas. Qual seria o impacto de viver abertamente (de forma pública) essa condição nas percepções subjetivas de qualidade de vida e esperança? Teriam os envelhescentes que se relacionam com pessoas do mesmo sexo de modo secreto/ privado percepções desvantajosas destas variáveis?

Diante destas lacunas, o objetivo desta pesquisa foi contrastar os níveis de esperança e a qualidade de vida em um grupo de sujeitos envelhescentes que se relacionam com pessoas do mesmo sexo de forma pública com um grupo de pessoas que vivem secretamente esta experiência.

\section{Método}

\section{Delineamento do Estudo}

Tratou-se de uma pesquisa quantitativa, descritiva de corte transversal com abrangência nacional Brasil - subsidiada pela utilização das plataformas digitais.

\section{Participantes}

A amostra do estudo foi composta por homens envelhescentes que se relacionavam com pessoas do mesmo sexo ( $n=103)$, com idades que variaram entre 40 e 65 anos, de ambos os sexos, e que faziam uso de plataformas/mídias digitais para encontrar parceiros. A amostra foi dividida em dois grupos:

a) GAon: pessoas que mantinham a homossexualidade de forma pública/aberta à sociedade $(n=52)$ e, b) GFoff: pessoas supostamente "heterossexuais" que recorriam anonimamente à internet/sites de relacionamento para encontrar parceiros/as do mesmo sexo em segredo (de modo privado) $(n=51)$.

\section{Procedimentos para a Coleta de Dados}

Esta pesquisa recebeu apoio financeiro da Fundação de Amparo à Pesquisa do Estado de São Paulo (FAPESP).

Os sujeitos que participaram do estudo eram usuários de duas plataformas nacionais de relacionamento, o Disponível.com e as salas de bate-papo do portal Universo Online ${ }^{\circledR}$ (UOL). Por meio das plataformas, os possíveis sujeitos de pesquisa eram abordados e convidados a participar do estudo. A coleta de dados ocorreu de forma online. O sujeito, antecipadamente à coleta, foi informado sobre a pesquisa e o seu consentimento online foi registrado por meio do botão de aceite clicado abaixo do Termo de Consentimento Livre e Esclarecido (TCLE), disponível na plataforma utilizada.

Por conseguinte, foram coletados os dados utilizando um Questionário de Caracterização dos Participantes, a Escala de Esperança de Herth (EEH) e o Instrumento de Avaliação de Qualidade de Vida (WHOQOL-bref), por intermédio da plataforma internacional Survey Monkey ${ }^{\circledast}$, versão Gold, for Windows ${ }^{\text {TM }}$. Nesta, os instrumentos foram respondidos e o pesquisador esteve acessível para auxiliar o sujeito, quando ocorreram dúvidas em relação às questões presentes nos instrumentos. O Skype ${ }^{T M}$ foi utilizado na medida em que se fez necessário um diálogo direto entre pesquisador-sujeito da pesquisa e vice-versa, principalmente, no que se referiram a eventuais perguntas, esclarecimentos e dúvidas.

\section{Instrumentos}

Questionário de Caracterização dos Participantes. Teve como finalidade a coleta de dados pessoais e sociodemográficos. Para o preenchimento do questionário, foram solicitados os seguintes dados: nome, sexo, idade, escolaridade, estado conjugal, número de filhos, estrutura familiar (quem são as pessoas que moram na mesma casa), problemas de saúde (se apresenta ou não algum problema de saúde autorrelatado) e religiosidade.

Escala de Esperança de Herth (EEH). É uma escala de autorrelato de origem americana, desenvolvida por Herth (1992) e validada no Brasil por Sartore e Grossi (2008), que quantifica a esperança. A EEH foi selecionada como instrumento de avaliação do nível de 
esperança por ser amplamente utilizada e reconhecida internacionalmente. No Brasil, a escala foi utilizada em pacientes oncológicos e diabéticos, durante o processo de validação (Sartore \& Grossi, 2008). Essas autoras relatam que a EEH mostra-se útil para avaliar o nível de esperança, tendo como vantagens: ser confiável e válida, ser curta e de fácil entendimento. A EEH possui 12 itens, escritos de forma afirmativa na qual a gradação dos itens se faz em uma escala Likert de 4 pontos, em que 1 indica "discordo completamente" e 4 indica "concordo completamente". Há dois itens, a afirmação de número 3 e a de número 6 , que apresentam escores invertidos. O escore total varia de 12 a 48 sendo que quanto maior o escore, mais alto o nível de esperança.

WHOQOL-bref. Instrumento genérico de avaliação da qualidade de vida. Foi desenvolvido pelo Grupo de Qualidade de Vida da Organização Mundial de Saúde em 1998 pela necessidade de um instrumento de rápida aplicação, trata-se da versão abreviada do WHOQOL-100, que possui 26 questões. Destas, duas questões são gerais sobre qualidade de vida e as demais 24 representam cada uma das 24 facetas que compõem o instrumento original e quatro domínios: físico, psicológico, relações sociais e meio ambiente, (WHOQOL, 1998). No Brasil, foi validado por Fleck et al. (2000). Os dados são avaliados a partir da transformação das respostas em escores por domínios que variam na escala de $0=$ pior a $100=$ melhor .

Critério de Classificação Econômica Brasil. Foi utilizado para avaliar o nível socioeconômico, por meio do poder aquisitivo familiar, baseando-se na quantidade de bens de consumo duráveis, do grau de instrução do chefe da família e outros fatores como a presença de empregada mensalista. Este critério divide a população em oito níveis ( $A 1, A 2, B 1, B 2, C 1, C 2$, D e E). Os critérios para classificação social no Brasil foram estabelecidos pela Associação Brasileira de Anunciantes (ABA), pela Associação Nacional das Empresas de Pesquisa de Mercado (ANEP) e pela Associação Brasileira dos Institutos de Pesquisa de Mercado (ABIPEME) com base no levantamento socioeconômico de 2010 (Associação Brasileira de Empresas de Pesquisa, 2012).

\section{Análise dos dados}

Os resultados foram analisados com auxílio do programa Statistical Package for the Social Sciences ${ }^{\circledast}$ (SPSS), versão 13.0. Foram realizadas análises estatísticas (Descritivas, Teste de Mann-Whitney e Análise correlacional de Spearman).

\section{Aspectos Éticos}

Todas as etapas deste trabalho obedeceram às diretrizes da Resolução 196/96 (versão 2012) e Resolução 466/2012. O projeto foi submetido e aprovado pelo Comitê de Ética em Pesquisa em Seres Humanos (CEP) da universidade sede da pesquisa (parecer número 300.177/2013). Todos os sujeitos do estudo foram informados dos objetivos do trabalho, consultados sobre a disponibilidade em participar do estudo e assegurados do sigilo das informações individuais. Os sujeitos responderam às entrevistas dentro da plataforma Survey Monkey ${ }^{\circledR}$, versão Gold, for Windows ${ }^{T M}$.

Os instrumentos utilizados na pesquisa são padronizados e validados no Brasil, com ampla utilização acadêmico-científica. A plataforma para a coleta de dados - Survey Monkey ${ }^{\circledR}$ - é usada por pesquisadores de vários países e, no Brasil, pela Universidade Estadual de Campinas e Universidade de São Paulo com aprovação em seus respectivos comitês de ética em pesquisa (Maciel, 2006).

É importante salientar que o sujeito só pôde participar da pesquisa mediante ao prévio consentimento. Não foi observado nenhum tipo de dano físico em se tratando dos procedimentos descritos neste estudo. Foi assegurado à pessoa, a qualquer momento durante a coleta de dados, o direito de interromper sua participação sem compromisso de justificativa.

\section{Resultados}

Características Sociodemográficas dos Envelhescentes que se Relacionam com Pessoas do Mesmo Sexo

Os 103 sujeitos entrevistados (GAon, GFoff) eram do sexo masculino. A média das idades do grupo GAon foi de 44,46 anos ( $D P=4,76, x$ mín $=40, x$ máx $=61$ ) e do grupo GFoff foi de 47,20 anos ( $D P=6,18, x \min =40$, xmáx = 62).

A escolaridade de ambos os grupos (GAon, GFoff) apresentou-se em níveis elevados. No GAon, 40,4\% (n $=21)$ tinham nível superior incompleto, $25 \%(n=13)$ nível superior completo, $23,1 \%(n=12)$ pós-graduação, 9,6\% $(n=5)$ ensino médio completo e 1,9\% ( $n=$ 1) ensino médio incompleto. No GFoff, $33,3 \%(n=17)$ apresentaram-se com nível de pós-graduação, 27,5\% ( $n$ $=14) \mathrm{com}$ nível superior completo, $17,6 \%(n=9) \mathrm{com}$ ensino médio completo, $15,7 \%(n=8)$ com nível superior incompleto, 3,9\% $(n=2)$ com ensino médio incompleto e $2,0 \%(n=1)$ com ensino fundamental completo. Importante perceber que o alto nível de escolaridade nos dois grupos (GAon, GFoff) foi um fator principal 
para a análise sobre a condição socioeconômica e o uso da tecnologia (mídia), abordados no tópico "discussão".

No que diz respeito ao número de filhos, observou-se que no GAon a média foi de 0,23 filhos $(D P=0,58, x \min =0, x m a ́ x=2)$ e no GFoff de 0,45 $(D P=0,92, x \operatorname{mí}=0, x$ máx $=3)$.

De acordo com o Critério de Classificação Econômica Brasil, foram registrados os seguintes resultados: (a) GAon: $30,8 \%$ na classe B2 $(n=16)$, $23,1 \%$ na classe C1 $(n=12), 21,2$ na classe B1 $(n=11)$, $13,5 \%$ na classe C2 $(n=7), 7,7 \%$ na classe A2 $(n=4)$ e $3,8 \%$ na classe D $(n=2)$; e (b) GFoff, $37,3 \%$ na classe B1 $(n=19), 25,5 \%$ na classe B2 $(n=13), 15,7 \%$ na classe C1 $(n=8), 11,9 \%$ na classe A2 $(n=6), 5,9 \%$ na classe C2 $(n=3)$ e $3,9 \%$ na classe $D(n=2)$.

A pesquisa contou com sujeitos provenientes de diferentes partes dos estados brasileiros. Do GAon, 38,5\% eram de São Paulo ( $n=20), 23,1 \%$ do Paraná $(n=12)$, $11,5 \%$ do Rio de Janeiro $(n=6), 9,6 \%$ da Bahia $(n=5)$, $5,8 \%$ do Rio Grande do Sul ( $n=3$ ), 3,8\% de Minas Gerais $(n=2)$ e 1,9\% $(n=1)$ dos demais estados (Espírito Santo, Goiás, Paraíba e Tocantins). Do GFoff, 52,9\% eram provenientes de São Paulo ( $n=27), 15,7 \%$ do Rio de Janeiro
( $n=8), 11,8 \%$ do Paraná $(n=6), 7,8 \%$ de Minas Gerais $(n=4), 4 \%$ de Pernambuco $(n=2)$ e $2,0 \%$ dos demais estados $(n=1)$, sendo: Distrito Federal, Pará, Pernambuco, Piauí, Rio Grande do Norte e Rio Grande do Sul.

Em se tratando do estado civil dos grupos, o GAon apresentou $63,5 \%(n=33)$ sujeitos na categoria solteiro, $32,7 \%(n=17)$ na categoria casado e $3,8 \%(n=2)$ na categoria divorciado. No GFoff , $60,8 \%$ $(n=31)$ dos sujeitos relataram estar solteiros, $21,6 \%$ $(n=11)$ casados, $15,7 \%(n=8)$ separados e os divorciados com igual porcentagem e quantidade sendo, por último, 2,0\% ( $n=1)$ viúvos.

\section{Análise da Qualidade de Vida do GAon e GFoff}

Os dados relativos às respostas obtidas pelo Instrumento de Avaliação de Qualidade de Vida WHOQOLbref dos grupos GAon e GFoff e as análises estatísticas comparativas podem ser observados na Tabela 1.

Quando analisados os escores totais de qualidade de vida, o GFoff apresentou escores totais mais altos nos domínios psicológico, relações sociais e meio ambiente, bem como na questão geral de qualidade de vida, quando comparado com o GAon.

Tabela 1. Análises Comparativas de Qualidade de Vida dos Grupos $G A_{\text {on }}$ e GF

\begin{tabular}{|c|c|c|c|c|c|c|}
\hline \multirow{2}{*}{ ITENS DE QUALIDADE DE VIDA } & \multirow{2}{*}{ GRUPO } & \multicolumn{2}{|c|}{ DADOS DESCRITIVOS } & \multicolumn{3}{|c|}{ ANÁLISE COMPARATIVA } \\
\hline & & M & DP & u & z & $\mathrm{p}$ \\
\hline \multirow{2}{*}{ Questão Geral de Qualidade de Vida (1ª . Questão) } & $\mathrm{GA}_{\text {on }}$ & 3,81 & 1,01 & \multirow[b]{2}{*}{1014,00} & \multirow[b]{2}{*}{$-2,119$} & \multirow[b]{2}{*}{0,034} \\
\hline & $\mathrm{GF}_{\text {off }}$ & 4,22 & 0,64 & & & \\
\hline \multirow[b]{2}{*}{ Questão Geral de Saúde (2 ${ }^{\text {a }}$. Questão) } & $\mathrm{GA}_{\text {on }}$ & 3,56 & 1,17 & \multirow[b]{2}{*}{1161,00} & \multirow[b]{2}{*}{$-1,152$} & \multirow[b]{2}{*}{0,249} \\
\hline & $\mathrm{GF}_{\text {off }}$ & 3,84 & 1,05 & & & \\
\hline \multirow[b]{2}{*}{ Domínio Físico } & $\mathrm{GA}_{\text {on }}$ & 70,94 & 17,35 & \multirow[b]{2}{*}{1144,00} & \multirow[b]{2}{*}{$-1,204$} & \multirow[b]{2}{*}{0,228} \\
\hline & $\mathrm{GF}_{\text {off }}$ & 75,71 & 12,61 & & & \\
\hline \multirow[b]{2}{*}{ Domínio Psicológico } & $\mathrm{GA}_{\text {on }}$ & 67,31 & 17,38 & \multirow[b]{2}{*}{933,00} & \multirow[b]{2}{*}{$-2,605$} & \multirow[b]{2}{*}{0,009} \\
\hline & $\mathrm{GF}_{\text {off }}$ & 75,98 & 11,60 & & & \\
\hline \multirow[b]{2}{*}{ Domínio Relações Sociais } & $\mathrm{GA}_{\text {on }}$ & 62,10 & 22,08 & \multirow[b]{2}{*}{1028,00} & \multirow[b]{2}{*}{$-1,986$} & \multirow[b]{2}{*}{0,047} \\
\hline & $\mathrm{GF}_{\text {off }}$ & 70,59 & 20,67 & & & \\
\hline \multirow[b]{2}{*}{ Domínio Meio Ambiente } & $\mathrm{GA}_{\text {on }}$ & 60,61 & 16,30 & \multirow[b]{2}{*}{994,00} & \multirow[b]{2}{*}{$-2,197$} & \multirow[b]{2}{*}{0,028} \\
\hline & $\mathrm{GF}_{\text {off }}$ & 67,98 & 14,69 & & & \\
\hline
\end{tabular}

\section{Análise da Esperança do GAon e GFoff}

As análises sobre a esperança a partir das respostas dos grupos GAon e GFoff foram obtidas por meio da Escala de Esperança de Herth (EEH). Os dados tabulados em relação às questões da escala podem ser observados na Tabela 2.
Quando analisados os escores totais de esperança obtidos pela EEH, vê-se a média do GFoff de 42,94 pontos $(D P=5,081, x$ mín $=23, x$ máx $=48)$ e para o GAon de 41,08 pontos $(D P=4,338, x$ mín $=32, x$ máx $=48)$. Esta diferença é estatisticamente relevante $(U=892,500 ; z=-2,873 ; p=$ $0,004)$, ou seja, a esperança do GFoff é maior que a do GAon. 
Esperança e qualidade de vida de envelhescentes que se relacionam com pessoas do mesmo sexo

\section{Discussão}

É possível perceber que a web amplia o território das relações homoeróticas e cria possibilidades inimagináveis à luz dos espaços públicos. Por diversas razões, as pessoas encontram na internet uma nova forma para encontrar parceiros, socializar e criar laços de amizade sem serem marcados pela exposição pública de seus desejos (Miskolci \& Pelúcio, 2009). Nota-se que as mídias digitais possibilitaram o alargamento da sociabilidade homoerótica. A internet e seus espaços criaram elementos de resistência ao estigma, de convivência e de estabelecimento das buscas, uma vez que os ambientes face a face reunidos aos virtuais combatem a segregação, o isolamento e a intolerância que marca territorialidades diversas (Simões \& França, 2005).

A presente pesquisa mostra este novo espaço de sociabilidade utilizado por homens homossexuais de meia-idade e idosos como forma alternativa aos circuitos tradicionais. Porém, o espaço online é acompanhado por um recorte de classe social e escolaridade, se comparados com o restante da população brasileira na mesma geração. Com a popularização do uso dos computadores, das redes sociais e do poder de consumo, muitos pontos de acesso foram criados em todo o Brasil - 56 milhões até outubro de 2012 -, entretanto, ainda é perceptível que o acesso tem um recorte de classe (Instituto Brasileiro de Opinião Pública e Estatística, 2013). No Sudeste 51,5\% dos domicílios têm acesso à internet, o Sul apresenta $42,9 \%$ e o Centro-Oeste $40,7 \%$. As regiões Norte e Nordeste apresentam, respectivamente, 29,2\% e 20,7\% (Instituto de Pesquisa Econômica Aplicada, 2014).

Herdeiros distantes do Pink Money, notadamente pela expansão comercial de serviços de consumo para homossexuais em fins dos anos 1970 e do desenvolvimento tecnológico, os aplicativos e os sites de encontros centrados nas buscas homoeróticas tendem a incorporar concepções mercadológicas de corpo, criando uma imagética modelar em torno do desejo e das preferências. Sujeitos mais velhos, sobretudo aqueles acima dos quarenta e cinco anos, encontrariam ao mesmo tempo uma série de dilemas e desafios no que toca aos padrões imagéticos de corpo, uma vez que o processo de envelhecimento pressupõe mudanças corporais substantivas, as quais são altamente desvalorizadas dentro dessas plataformas, prevalecendo um escrutínio da "fita métrica" (Sabino, 2000) que reflete uma imagética do corpo jovem, muscular e sarado (Miskolci, 2014; Zago, 2013).
Por outro lado, o recorte desta pesquisa, a partir de uma amostra de interlocutores com elevado capital educacional e econômico, não é um dado que pode ser generalizado entre os homossexuais mais velhos atualmente online - tampouco sobre as demais pessoas. Por ser uma metodologia de amostras convenientes, este fato pode ter influenciado a investigação, uma vez que os respondentes foram pessoas com elevado nível intelectual que se sentiam atraídos pela possibilidade de participar de pesquisas acadêmicas (Marotti et al., 2008).

Os testes comparativos demonstraram que a internet como uma possibilidade para encontrar parceiros tem associação com o critério da idade $(U=$ $1000,000, z=-2,172, p=0,030)$. As pessoas que vivem a homossexualidade de forma secreta são mais velhas quando comparadas com o grupo que vive a homossexualidade de forma pública - mais jovens. Viver uma sexualidade que, até menos de meio século, era tida como sinônimo de doença, pecado e desvio é colocar em xeque questões mais amplas e igualmente complexas. De tal modo, a geração que viveu o pânico sexual da AIDS e as políticas higienistas que patologizaram as homossexualidades até meados dos anos 90 , especialmente pela disseminação do HIV nos anos 80 , podem encontrar no sigilo um modo mais seguro de vivenciar suas experiências; sobretudo, pela não visibilização de uma sexualidade historicamente reconhecida como anormal, abjeta e, mesmo, perigosa (Morton, Jeyasingham, \& Hicks, 2013).

Consideramos importante refletir sobre o impacto da Aids, pois, como o estudo demonstra, as pessoas que se relacionam afetivo e sexualmente com o mesmo sexo de forma secreta são mais velhas em termos etários. Este dado é significativo e traz à baila importantes estudos socioantropológicos como os de Néstor Perlongher (2008), Michael Pollak (1990), Richard Parker e Peter Aggleton (2001), Larissa Pelúcio (2009), Júlio Assis Simões e Regina Facchini (2009) e Richard Miskolci (2013); tais autores têm discutido a questão do "desejo" pelo mesmo sexo e a própria noção de (homo)sexualidade como um fenômeno intrinsecamente social e histórico. E tal qual um fenômeno social em que indivíduos podem atribuir significados diferentes e esses mesmos significados podem mudar, propusemo-nos a investigar a esperança e a qualidade de vida a partir das percepções subjetivas em dois grupos que historicamente viveram a mesma experiência geracional - o impacto da epidemia de HIV-Aids nos anos 1980 
e o advento das mídias digitais pela expansão da internet comercial a partir de 1997 no Brasil.

O grupo que vive a homossexualidade de forma secreta (GFoff), pelos dados obtidos neste estudo, tem percepções mais satisfatórias de qualidade de vida e esperança em relação aos que vivem a homossexualidade de forma aberta à sociedade (GAon). Este dado propicia novos questionamentos sobre possíveis variáveis que influenciariam estes resultados: a organização familiar, organização social, ordem cultural etc. O GAon, para além de toda a visibilidade que assumem, ainda são mais vulneráveis às condições adversas - ausência da família e possível exposição às dificuldades em relação à homossexualidade.

Os dilemas em torno das relações homoeróticas, do segredo e da revelação, da rede de suporte social e da família, envolvem uma trama ampla de relações as quais modulam as expectativas amorosas e sexuais de homens envelhescentes e idosos. Assumir-se ou "sair do armário" não é necessariamente um processo positivo e inteiramente acabado. Segundo Eve K. Sedgwick (2007) trata-se de um processo de constante negociação. A cada relação diária nos deparamos com um novo "armário" em nossas vidas, em que escolher permanecer dentro ou sair fora dele não reflete necessariamente uma escolha individual e, portanto, pessoal. Ao fim e ao cabo Sedgwick (2007) demonstra que o segredo, aparentemente como um segredo pessoal, engendra um processo social de negociação, uma vez que revelar-se homossexual nunca é uma decisão puramente emocional e de um único sujeito, mas que é socialmente exercitada por meio de relações assimétricas de poder.

Assumir-se num contexto hostil em que as redes sociais e familiares estão enfraquecidas, pode fazer com que haja alterações negativas nas dinâmicas de suporte social e, sobretudo, na qualidade de vida dos sujeitos. Segundo Ceará e Dalgalarrondo (2010), o suporte social na velhice é um fator importante para a qualidade de vida. "Nesse sentido, a ausência de suportes sociais favoráveis, em um contexto hostil e preconceituoso à orientação homossexual, pode contribuir para o sofrimento" (Ceará \& Dalgalarrondo, 2010, p. 118).

O estudo também permitiu constatar empiricamente que há uma incidência considerável de pessoas casadas que recorrem aos sites de busca de parceiros para relações homoeróticas de maneira secreta. Este dado possibilita entrever que esses novos espaços online são também demandados por pessoas em relacionamentos monogâmicos e supostamente heterossexuais, as quais buscam anonimamente um parceiro para relação rápida e sem compromisso.

A preservação da relação heterossexual via casamento, neste sentido, parece guardar a segurança e as facilidades no espaço público, até mesmo no que diz respeito ao apoio e suporte social da família, enquanto a relação homoerótica via sites de relacionamento, de outro modo, exercita o sentimento de agência dos sujeitos. A despeito disso, concordamos com Rich (1993) no que concerne à noção de heterossexualidade compulsória: o casamento, na esfera pública, mantém a heterossexualidade aparente e presumida, à medida que o desejo pelo mesmo sexo é vivenciado de maneira secreta, não confrontando as normas sociais de gênero e sexualidade.

Nesse sentido, as subjetividades passam a ser moldadas num momento distinto àquele vivenciado nos anos 1970/80 e 1990, e que baliza tecnologias comunicacionais as quais (re)configuraram noções binárias e históricas entre público/privado, visibilidade/invisibilidade, segredo/revelação, homossexualidade/heterossexualidade etc. Essa mesma mudança favoreceu um crescente descolamento da sociabilidade anterior, que era marcada pela busca por sexo em lugares públicos (cruising), criando outros circuitos mais individualizados e acoplados a uma arquitetura comunicacional afeita ao mercado, ao sexo rápido, casual e sem compromisso (hook up) (Miskolci, 2014; Nogueira, 2016).

\section{Conclusão}

A partir dos objetivos propostos para este estudo, os resultados possibilitaram as seguintes conclusões pontuais: (a) viver a homossexualidade de forma aberta (pública) e fechada (em segredo) traz percepções distintas de qualidade de vida e esperança; (b) renda e escolaridade são indicadores importantes quando se analisa transversalmente o acesso à internet e a própria aquisição de recursos e bens de consumo duráveis (computador, plano de internet e provedor); (c) a experiência do segredo, da recusa a assumir-se como homossexual não é um preditor de qualidade de vida e esperança baixas; (d) o grupo que vive a homossexualidade em segredo apresenta melhores percepções de qualidade de vida e esperança em relação aos que vivem a homossexualidade de forma pública; (e) os interlocutores que vivem secretamente a experiência online da homossexualidade, geralmente, são mais velhos.

O estudo aqui desenvolvido não pretende formar uma "tábua rasa" e generalizar dados de cunho subjetivo 
como determinantes absolutos, objetivos e padronizados: a diretiva foi deste modo, a de conhecer percepções de qualidade de vida e esperança no que se refere à experiência do segredo entre homens homossexuais de meia-idade e idosos. Por ser um tema pouco explorado na área da gerontologia, especialmente no que se refere ao estudo combinado acerca da qualidade de vida e esperança, o desenho do estudo aqui desenvolvido bem como os dados gerados são inéditos para a área da gerontologia no Brasil.

Vale ressaltar que os resultados encontrados nesta pesquisa não têm a intenção de incitar maneiras de viver a homossexualidade (aberta ou em segredo) para fomento da qualidade de vida e esperança e/ou expressar quaisquer julgamentos morais a respeito dessas vivências.

Reforça-se, portanto, o diálogo com as demais áreas do conhecimento para elucidar a interdisciplinaridade e a problematização de temas inéditos no Brasil. Investigações mais acuradas, pesquisas etnográficas e outras formas de análise dessa dinâmica entre o "eu" público (aberto) e privado (em segredo) no processo de envelhecimento homossexual são cruciais. A incursão de pesquisas que tragam a dimensão do suporte/ apoio social e funcionalidade familiar para compor a investigação e aprimorar a reflexão sobre a temática é indispensável em trabalhos futuros.

\section{Referências}

Associação Brasileira de Empresas de Pesquisa (2012). Critério de Classificação

Econômica Brasil (CCEB). Recuperado de http://www.abep.org/novo/ Content.aspx?SectionID $=301$

Ceará, A. D. T., \& Dalgalarrondo, P. (2010). Transtornos mentais, qualidade de vida e identidade em homossexuais na maturidade e velhice. Revista de Psiquiatria Clínica, 37(3), 118-123. doi: 10.1590/ S0101-60832010000300005.

Fleck, M. (2008). Problemas conceituais em qualidade de vida. In M. P. A. Fleck (Org.), A avaliação de qualidade de vida:guia para profissionais da saúde (pp. 19-28). Porto Alegre: Artmed.

Fleck, M., Louzada, S., Xavier, M., Chachamovich, E., Vieira, G., Santos, L., \& Pinzon, V. (2000). Application of the Portuguese version of the abbreviated instrument of quality life WHOQOLbref. Revista de Saúde Pública, 34(2), 178-183. doi: 10.1590/ S0034-89102000000200012.

Guimarães, C. D. (2004). O homossexual visto por entendidos. Rio de Janeiro: Garamond.

Herth, K. (1992). Abbreviated instrument to measure hope: development and psychometric evaluation. Journal of Advanced Nursing, 17(10), 1251-1259. doi: 10.1111/j.1365-2648.1992.tb01843.x.

Illouz, E. (2012). Why love hurts? A sociological explanation. Londres: Polity Press.
Inouye, K. (2008). Educação, qualidade de vida e Doença de Alzheimer: visões de idosos e seus familiares (Dissertação de Mestrado). Recuperado de https://repositorio.ufscar.br/bitstream/handle/ ufscar/2998/2179.pdf?sequence=1

Instituto Brasileiro de Opinião Pública e Estatística (2013). Número de pessoas com acesso à internet passa de 100 milhões. Recuperado de http://www.ibope.com.br/pt-br/noticias/paginas/numero-de-pessoas-com-acesso-a-internet-passa-de-100-milhoes.aspx

Instituto de Pesquisa Econômica Aplicada (2014). Sistemas de indicadores de percepção social.Recuperado de http://www.ipea.gov. br/agencia/images/stories/PDFs/SIPS/140313_sips_telecomunicacoes.pdf

Maciel, E. S. (2006). Qualidade de vida: análise da influência do consumo de alimentos e estilo de vida (Dissertação de Mestrado). doi: 10.11606/D.11.2006.tde-13112006-092423

Marotti, J., Galhardo, A. P. M., Furuyama, R. J., Pigozzo, M. N., Campos, T. N. D., \& Laganá, D. C. (2008). Amostragem em pesquisa clínica: tamanho da amostra. Revista de Odontologia da Universidade Cidade de São Paulo, 20(2), 186-194. Recuperado de http://arquivos.cruzeirodosuleducacional.edu.br/principal/old/revista_odontologia/pdf/maio_agosto_2008/Unicid_20(2_12)_2008.pdf

Mendes, E. G., Nunes, L. R. D. O. D., \& Ferreira, J. R. (2002). Diagnóstico e caracterização de indivíduos com necessidades educacionais especiais: produção científica nacional entre 1981 e 1998. Temas em Psicologia, 10(1), 11-25. Recuperado de http://pepsic.bvsalud.org/scielo.php?script=sci_arttext\&pi$\mathrm{d}=$ S1413-389X2002000100002\&lng=pt\&nrm=iso\&tlng=pt

Miskolci, R. (2013). Networks of desire: the specter of AIDS and the use of digital media in the quest for secret same-sex relations in São Paulo. Vibrante - Virtual Brazilian Anthropology, 10(1), 40-70. doi: 10.1590/S1809-43412013000100002.

Miskolci, R. (2014). San Francisco e a nova economia do desejo. Lua Nova: Revista de Cultura e Política, 91, São Paulo, 269-295. doi: $10.1590 /$ S0102-64452014000100010

Miskolci, R., \& Pelúcio, L. (2009). A prevenção do desvio: o dispositivo da AIDS e a repatologização das sexualidades dissidentes. Sexualidad, Salud y Sociedad, 1, 125-157. Recuperado de http:// www.e-publicacoes.uerj.br/index.php/SexualidadSaludySociedad/ article/view/29/26

Morton, J., Jeyasingham, D., \& Hicks, S. (2013). The social work of sexuality: rethinking approaches to social work education. Health and Social Care Education, 2(2), 16-19. doi: 10.11120/ hsce.2013.00027

Mota, M. P. (2009). Homossexualidade envelhecimento: algumas reflexões no campo da experiência. SINAIS - Revista de Ciências Sociais, 1(6), 26-51. Recuperado de http://periodicos.ufes.br/sinais/ article/view/2752/2220

Neri, A. L. (2008). Palavras-chave em gerontologia. Campinas: Alínea.

Nogueira, G. (2016). Caças e pegações online: subversões e reiterações de gêneros e sexualidades. Rio de Janeiro: Multifoco.

Parker, R., \& Aggleton, P. (2001). Estigma, discriminação e AIDS. In R. Parker \& P. Aggleton (Orgs.), Coleção ABIA, cidadania e direitos (pp. 5-38). Rio de Janeiro: Associação Brasileira Interdisciplinar de AIDS.

Pelúcio, L. (2009). Abjeção e desejo: uma etnografia travesti sobre o modelo preventivo de AIDS. São Paulo: Annablume Editora.

Perlongher, N. (2008). O negócio do michê: a prostituição viril em São Paulo. São Paulo: Perseu Abramo. 
Pollak, M. (1990). Os homossexuais e a Aids: sociologia de uma epidemia. São Paulo: Estação Liberdade.

Resolução 196/96 versão 2012. Diretrizes e normas regulamentadoras de pesquisas envolvendo seres humanos. Brasília, DF: Conselho Nacional de Saúde. Recuperado de

http://conselho.saude.gov.br/web_comissoes/conep/aquivos/resolucoes/23_out_versao_final_196_ENCEP2012.pdf

Resolução 466/2012. Diretrizes e normas regulamentadoras de pesquisas envolvendo seres humanos. Brasília, DF: Conselho Nacional de Saúde. Recuperado de http://conselho.saude.gov.br/resolucoes/2012/Reso466.pdf

Rich, A. (1993). Compulsory heterosexuality and lesbian existence. In: B. C. Gelp \& A. Gelp (Orgs.), Adrienne Rich's Poetry and Prose. Nova lorque/Londres: W.W. Norton \& Company.

Sabino, C. (2000). As drogas de Apolo: o consumo de anabolizantes em academias de musculação (Dissertação de Mestrado não publicada). Universidade Federal do Rio de Janeiro, Rio de Janeiro.

Sartore, A. C., \& Grossi, S. A. A. (2008). Escala de Esperança de Herth: instrumento adaptado e validado para a língua portuguesa. Revista da Escola de Enfermagem da USP, 42(2), 227-32. doi: 10.1590/ S0080-62342008000200003

Scalon, C., \& Salata, A. (2012). Uma nova classe média no Brasil da última década? O debate a partir da perspectiva sociológica. Revista Sociedade e Estado, 27(2), 387-407. doi: 10.1590/ S0102-69922012000200009

Sedgwick, E. K. (2007). A epistemologia do armário. Cadernos Pagu, 28, 19-54. doi: 10.1590/S0104-83332007000100003
Simões, J. A. (2004). Homossexualidade masculina e curso da vida:pensando idades e identidades sexuais. In A. Psicitelli, M. F. Gregori, \& S. Carrar (Orgs.), Sexualidade e saberes: convenções e fronteiras (pp. 2-30). Rio de Janeiro: Garamond.

Simões, J. A.; \& Facchini, R. (2009). Nas trilhas do arco-íris: do movimento homossexual ao LGBT. São Paulo: Perseu Abramo.

Simões, J. A.; \& França, I. L. (2005). Do gueto ao mercado. In J. N. Green \& R. Trindade (Orgs.), Homossexualismo em São Paulo e outros escritos (pp. 309-333). São Paulo: Editora Unesp.

Sontag, S. (1989). AIDS and Its Metaphors. Nova lorque: Farrar, Straus and Giroux.

Souza, J. (2012). Os batalhadores brasileiros: nova classe média ou nova classe trabalhadora. Belo Horizonte: UFMG.

The World Health Organization quality of life assessment (1995). The World Health Organization quality of life assessment (WHOQOL): Position paper from the World Health Organization. Social Science \& Medicine, 41(10), 1403-1409. doi: 10.1016/0277-9536(95)00112-K

The World Health Organization quality of life assessment (1998) Development of the World Health Organization WHOQOL-bref. Quality of Life Assessment. Psychological Medicine, 28(3), 551-558. Recuperado de https://www.cambridge.org/core/journals/psychological-medicine/article/development-of-the-world-health-organization-whoqolbref-quality-of-life-assessment/0F50596B33A1ABD59A6605C44A6A8F30

Zago, L. F. (2013). Os meninos - corpo, gênero e sexualidade através de um site de relacionamentos (Tese de Doutorado). Recuperado de http://hdl.handle.net/10183/70594 
João Paulo Ferreira da Silva, Mestre em Sociologia pelo Programa de Pós-Graduação em Sociologia (PPGS) do Centro de Educação

e Ciências Humanas (CECH) da Universidade Federal de São

Carlos (UFSCar), área de concentração Sociologia das Diferenças,

é Doutorando em Sociologia pelo Programa de Pós-Graduação

em Sociologia (PPGS) do Centro de Educação e Ciências Humanas

(CECH) da Universidade Federal de São Carlos (UFSCar), área de

concentração Sociologia Digital.

Endereço para correspondência: Rua José Aparecido Martins da Cruz, 576, São Pedro, Guatapará - SP. CEP 14115.000.

Telefone: 39731388.

E-mail: joaopauloferreira@outlook.com

Keika Inouye, Doutorado em Educação Especial pelo Programa de Pós-Graduação em Educação Especial (PPGEEs) do Centro de Educação e Ciências Humanas (CECH) da Universidade Federal de São Carlos (UFSCar), área de concentração Educação do Indivíduo Especial, é Professora Adjunta do Departamento de Gerontologia

(DGero) da Universidade Federal de São Carlos (UFSCar).

E-mail: keikain@ufscar.br

Fabiana de Souza Orlandi, Doutorado em Ciências pelo Programa de Pós-Graduação em Enfermagem (PPGE) da Escola de Enfermagem da Universidade de São Paulo (EEUSP), Área de Concentração - Cuidado em Saúde, é Professora Adjunta III do Departamento de Gerontologia (DGero) da Universidade Federal de São Carlos (UFSCar), é Professora Permanente do Programa de Pós-Graduação em Enfermagem (PPGEnf) e do Programa de Pós-Graduação em Gerontologia (PPGGero) da Universidade Federal de São Carlos (UFSCar).

E-mail: forlandi@ufscar.br

Sofia Cristina lost Pavarini, Doutora em Educação pela Universidade Estadual Paulista (UNICAMP) e Pós-Doutora em Gerontologia pela Universidade Estadual Paulista (UNICAMP), é Professora Titular na área de Saúde Mental e Envelhecimento do Departamento de Gerontologia da Universidade Federal de São Carlos (UFSCar), Professora do Departamento de Gerontologia da UFSCar e Coordenadora do Programa de Pós- Graduação em

Gerontologia da Universidade Federal de São Carlos (UFSCar).

E-mail: sofia@ufscar.br

Recebido em 17.Fev.16

Revisado em 27.Abr.17

Aceito em 08.Mai.17 